Methods Scottish respiratory trainees were emailed an online questionnaire in February 2021 to gather qualitative and quantitative data on their bronchoscopy training. The ten questions were designed to assess how many procedures trainees have done during the pandemic, how training has been affected, and how training could be improved.

Results 38 respiratory trainees responded from all deaneries in Scotland. Of these, 95\% said their training was affected by the pandemic. In addition, 92\% did not feel there was a clear curriculum for bronchoscopy training. Only 4 people $(11 \%)$ had done more than 50 bronchoscopies since the start of the pandemic and 23 people (61\%) had done less than 20. The main reasons cited for this were reduced number of lists, reduced number of patients per list and other clinical commitments (figure 1).

Most participants used informal feedback to measure their progress (79\%); the JRCPTB logbook was used the least (37\%) (figure 2). Every participant thought bronchoscopy training could be improved. Attending more lists, simulation training and improved methods of assessment were the most frequently selected options for improving training (figure 3). Conclusions Our data has indicated a need for change in bronchoscopy training. In particular we found trainees were dissatisfied with the curriculum and methods of assessment.

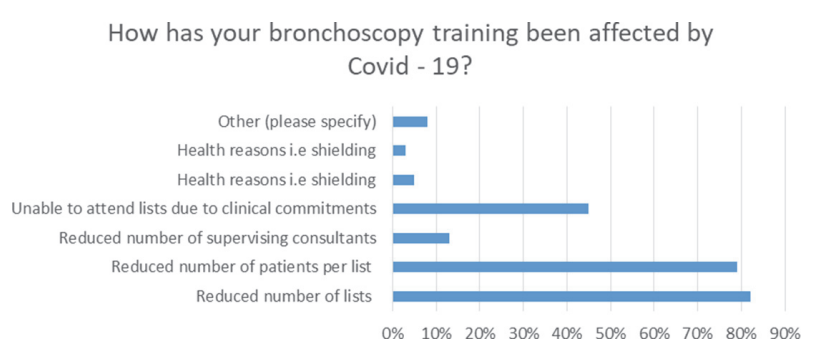

Abstract P175 Figure 1

How do you measure the progress of your bronchoscopy training?

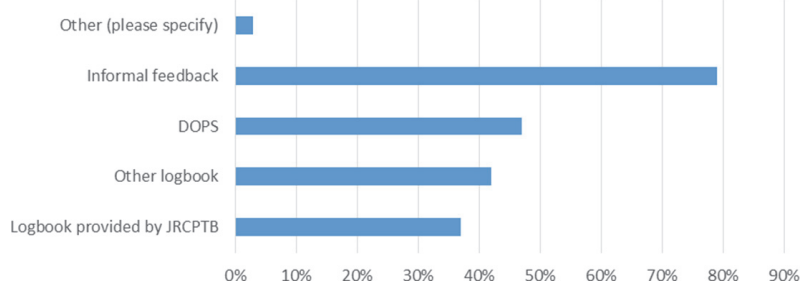

Abstract P175 Figure 2

How do you think bronchoscopy training could be improved? Please tick all that apply.

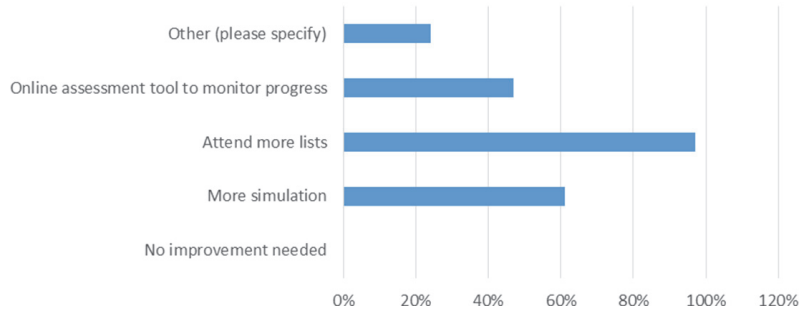

Abstract P175 Figure 3
From our literature search, UK bronchoscopy training lacks a clear and robust structure compared to other countries. This data will be used to support a proposal for a bronchoscopy simulation training programme.

\section{P176 THE RESTRUCTURING AND DEVELOPMENT OF A RESPIRATORY IN-REACH CONSULTATION SERVICE STAFFED BY ADVANCED CLINICAL PRACTITIONERS}

A Lee, B Jenkinson. Nottingham University Hospitals NHS Trust, Nottingham, UK

\subsection{6/thorax-2021-BTSabstracts.285}

Introduction The restructuring of Respiratory Services in response to COVID-19 led to the speciality moving to one campus, resulting in the loss of on-site respiratory services at the other campus, Consequentially there was a disparity in support provided to patients and medical staff, with inconsistent inpatient review depending on physician availability. To develop the highest quality service with equity of input a robust referral process with inpatient review led by respiratory ACPs and supported by Consultant physicians was developed.

Methods/Approach Advanced clinical practitioners provided a consistent inpatient referral service during three days per week; accepting, reviewing, discussing, and then managing referrals made via allied specialities to respiratory medicine, a role traditionally carried out by Registrars and Consultants To ensure autonomy of the role, it was essential the advice given by the ACP was safe and appropriate. Data was collected to evaluate the efficacy of the advice provided by the ACP. An additional survey was undertaken to gain evidence of national practice in this field which suggested the ACP team is at the forefront of developing innovative practice.

Results In 8 months the ACP team reviewed 419 patients; admissions were prevented advice regarding specialist treatment was provided, and timely transfer into the specialty was facilitated, including arranging follow up by community services or in consultant sub-speciality clinics. Twelve 'additional days' were covered to allow specialist registrars to attend training, improving MDT collaboration and consistency if care for patients.

Conclusion The introduction of an ACP-led referral service reduced the time from referral to patient review, freed up Consultant hours for other duties, and facilitated appropriate onward management of patients. Following the successful implementation of this ACP-led service the aim will now be to provide 5-day cover and collect more robust outcome measures to demonstrate improvement in patient outcomes.

\section{P177 ARE WARD ROUNDS A SOURCE OF LEARNING? TRAINEES PERCEPTION OF LEARNING KNOWLEDGE, SKILLS OR ATTITUDE DURING WARD ROUNDS IN A LARGE TERTIARY CARE HOSPITAL}

${ }^{1}$ A Khan, ${ }^{1} \mathrm{H}$ Jahdali, ${ }^{1}$ AS Harbi, ${ }^{1} \mathrm{~S}$ Al Yami, ${ }^{1} \mathrm{~A}$ Mutairi, ${ }^{2} \mathrm{H}$ Sher. ${ }^{1}$ King Abdulaziz Medical City, King Fahd National Guard Hospital, Riyadh, Saudi Arabia; ${ }^{2}$ York University, Toronto, Canada

\subsection{6/thorax-2021-BTSabstracts. 286}

Introduction Ward rounds (WRs) have been integral to the process of teaching and learning. WRs can also provide healthcare professionals with unique training opportunities at 